\title{
OSTHEOSYNTHESIS OF THE CALCANEUS WITH A C-NAIL
}

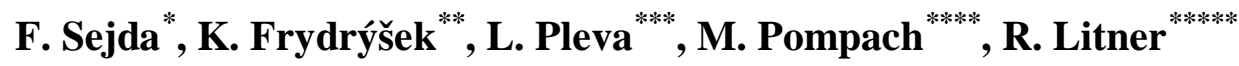

\begin{abstract}
This article deals with the strength analysis of an intramedullary nail (internal fixator), used in traumatology/orthopaedic for a broken heel bone (calcaneus). The application focuses on the unique miniinvasive C-NAIL produced by the company Medin a.s. (Nové mèsto na Moravě, Czech Republic). The focus is on types of calcaneal fractures and the possibilities of treating them, on the analysis of calcaneus load and the creation of a CAD-FEM model of the calcaneus from CT images (design - the engineeering point of view). Consequently, an analysis is carried out of the peripheral conditions including loading. The calculations were done on solid (, healthy") bones and bones cut into indidivual bone fragments (imitating broken bones), using the finite element method in the Ansys Workbench application.
\end{abstract}

\section{Keywords: Biomechanics, heel bone (calcaneus), heel nail, FEM, CT images, stress analyses.}

\section{Introduction}

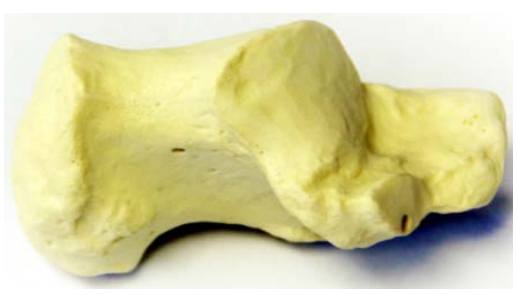

Fig. 1: Calcaneus (heel bone).

This article explains the aspects of biomechanics for the system of calcaneus (heel bone) and C-NAIL intramedullary bone nail (produced by the Czech company Medin a.s. in cooperation with Pardubice Regional Hospital, University Clinic in Dresden, VSB - Technical University of Ostrava \& University Hospital Ostrava). C-NAIL is used for treatment of intra-articular and extra-articular fractures of calcaneus. Fixation with C-NAIL is mini-invasive and based on the stabilization of bone fragments of the calcaneus in connection with fixation screws (i.e. angular stable connection).

The calcaneus, see Fig. 1, is the biggest and most massive foot bone. It is made up of articular surfaces, which are in contact with the surrounding bones (Martini, 2015, Frydrýšek1, 2018 \& Frydrýšek2, 2018). When walking on the heels, almost all the body weight is transferred there. If calcaneus is damaged, a small shift in the articular surfaces can lead to the formation of arthrosis, pain, and further fracturing, etc. The heel bone is directly under the skin and is not covered by muscles, only by a layer of fat, which in damaging the surface layers of the body leads to complications during healing of both the skin cover and the bone itself (Sejda, 2016). Fractures of the heel bone are most often caused by falling from a height. This is a serious injury where the patient may have difficulty even with top-quality treatment, the weight of the whole body is transferred by the crus and the ankle bone (talus) to the calcaneus, which is impacted

MSc. František Sejda: Faculty of Mechanical Engineering, VSB - Technical University of Ostrava, 17. listopadu 2172/15, 70800 Ostrava, CZ, frantisek.sejda@vsb.cz

** Assoc. Prof. Karel Frydrýšek, Ph.D., ING-PAED IGIP: Faculty of Mechanical Engineering, VSB - Technical University of Ostrava, 17. listopadu 2172/15, 70800 Ostrava, CZ, karel.frydrysek@vsb.cz \& Institute of Emergency Medicine, Faculty of Medicine, University of Ostrava, Syllabova 19, 70300 Ostrava, CZ, karel.frydrysek@vsb.cz

*** M.D. Martin Pompach, Ph.D.: Pardubice Regional Hospital, Kyjevská 44, 53003 Pardubice, CZ m.pompach@gmail.com

**** Assoc. Prof. M.D. Leopold Pleva, Ph.D.: Trauma Centre, University Hospital Ostrava, 17. listopadu 1790, 708 52, Ostrava, CZ \& Institute of Emergency Medicine, Faculty of Medicine, University of Ostrava, Syllabova 19, 70300 Ostrava, CZ, leopold.pleva@fno.cz

${ }^{* * * * * *}$ M.D. Roman Litner: Trauma Centre, University Hospital Ostrava, 17. listopadu 1790, 708 52, Ostrava, CZ, roman.litner@fno.cz 


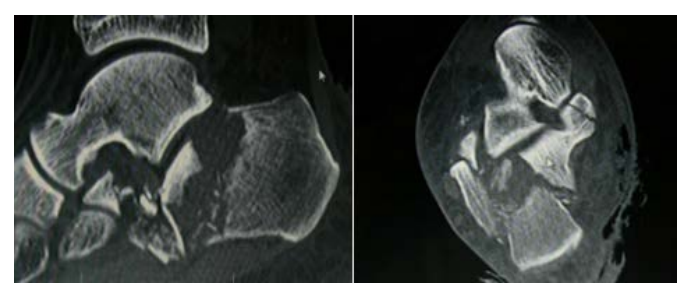

Fig. 2 Heel bone fracture $x$-rays images

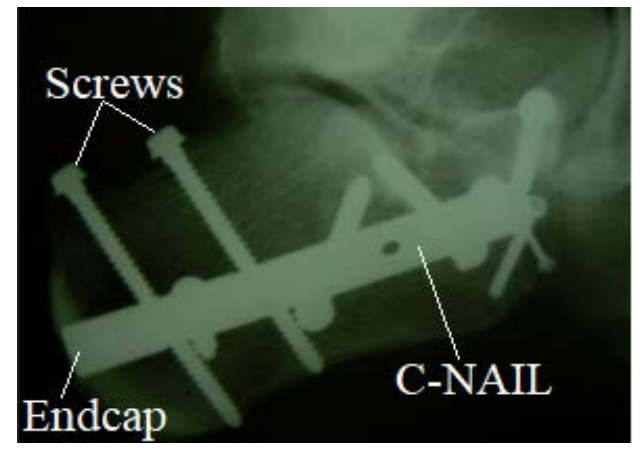

Fig. 3: Application of the heel nail C-NAIL.

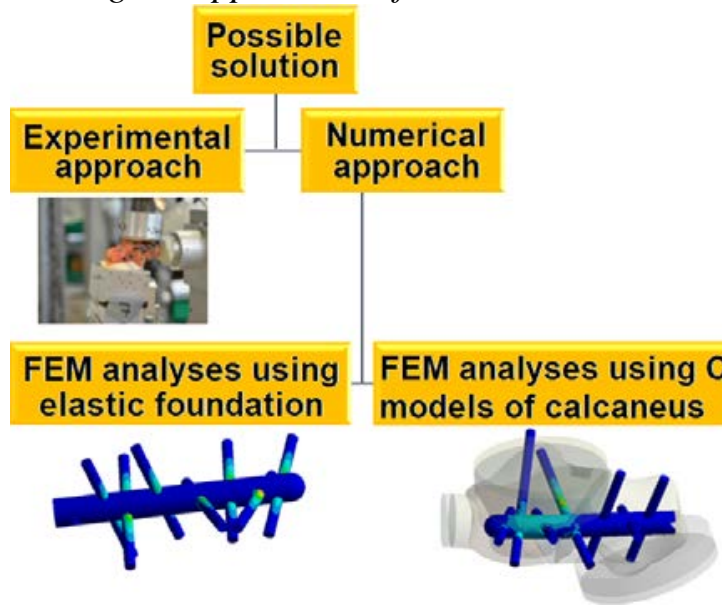

Fig. 4: Biomechanical approaches applied for

$$
\text { C-NAIL. }
$$

by ground resistance, and partially breaks or is broken into two or more fragments. Other causes of calcaneal fractures include sports injuries, car accidents, explosion on the ground etc. The location of the limbs during an accident determines the types of fractures and subsequent dislocations. Quite often calcaneal fractures are associated with other traumas too. Calcaneal fractures are diagnosed according to their anamnesis, considering the trauma mechanism, the clinical signs (subjective and objective symptoms) and mainly using $\mathrm{x}$-ray imaging methods, see Fig. 2, and CT (Computer tomography). Typical clinical signs include pain, limited to the impeded limb load, limited leg mobility, progressive soft tissue swelling, underlying ankle hematoma, flattening of the foot arch and pain in the subtalar area extending to the entire back of the foot. Fractures of the calcaneus may be extraarticular (abruptions of the edges, protrusions), intraarticular without major dislocation, and without reduction of the heel bone and intraarticular with a dislocation of fragments and heel bone reduction (Stehlík et al., 2005). Osteosynthesis of the heel bone fractures can be carried out using the surgical techniques of external and internal fixation, that consist predominantly in the application of a heel plate or a new C-NAIL heel nail, see Fig. 3.

The principle of C-NAIL application, see Fig. 3, is to stabilize the fractured heel bone fragments using a nail in connection with 5 - 7 locking screws, with which it forms an angular stable fixation. Maximum stability is achieved by fixating sustentacular fragments through the nail using two additional screws which are guided using a target. For fragment replication it is enough to have a small lateral approach from the apex of the outer ankle bone towards the $5^{\text {th }}$ metatarsus base of approx. $30 \mathrm{~mm}$, and there are only a few mini-incisions to guide the provisional K-wire of the nail itself and the individual screws. This mini-invasiveness considerably reduces the risk of infection. Another important advantage is the stability of the implant and thus the solid fixation of the heel bone fragments. C-NAIL has been designed separately for the left side (marked „L“) and for the right side (marked „R“). The nail diameter is $8 \mathrm{~mm}$ and the max. length is $65 \mathrm{~mm}$. The nail has 7 openings (holes) for fixating in the calcanUS.

Worldwide, there is currently Calcanail (France) and блокований стрижень (Ukraine), they are out of scope of this article. Biomechanical approaches applied for C-NAIL are shown in Fig. 4 and in the following chapter.

\section{Biomechanics of calcaneus and C-NAIL}

To create high-quality heel bone models, CT images (sequential cuts) of the lower limbs were used. Materialise Mimics software was used for obtaining CAD models of the calcaneus. For a correctly formed bone model it was necessary to separate thick bone tissue from the other soft tissues in the individual CT sections. The Mimics software used for this separation is based on the Housfield unit, which is the density of the individual voxels (the unit volume of tissue). The result of this separation are the CAD models, see Fig. 5, which were subjected to FEM analyses.

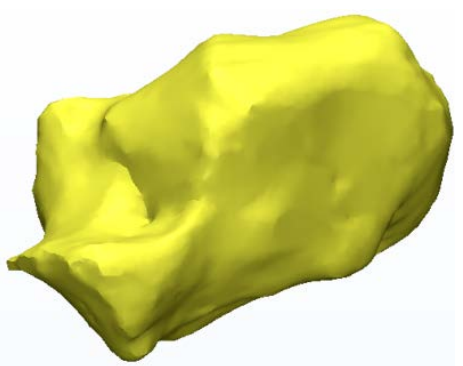

Fig. 5: CAD model of calcaneus. 
The severity of this operation depends on the quality of the CT images supplied (Keyak, 2003 and Yosibash, 2012).

For the initial analysis bone material was chosen as homogeneous isotropic material because of the complexity of the numerical model making it easier to provide for adjustment, with elastic modulus $15000 \mathrm{MPa}$ and Poisson number 0.33. The FEM model comes from the testing apparatus described in the experiment (Richter, 2006), where there was interaction between the heel bone and other leg bones (of the foot) and the base was replaced by veterinary cement bodies, see Fig. 6 .

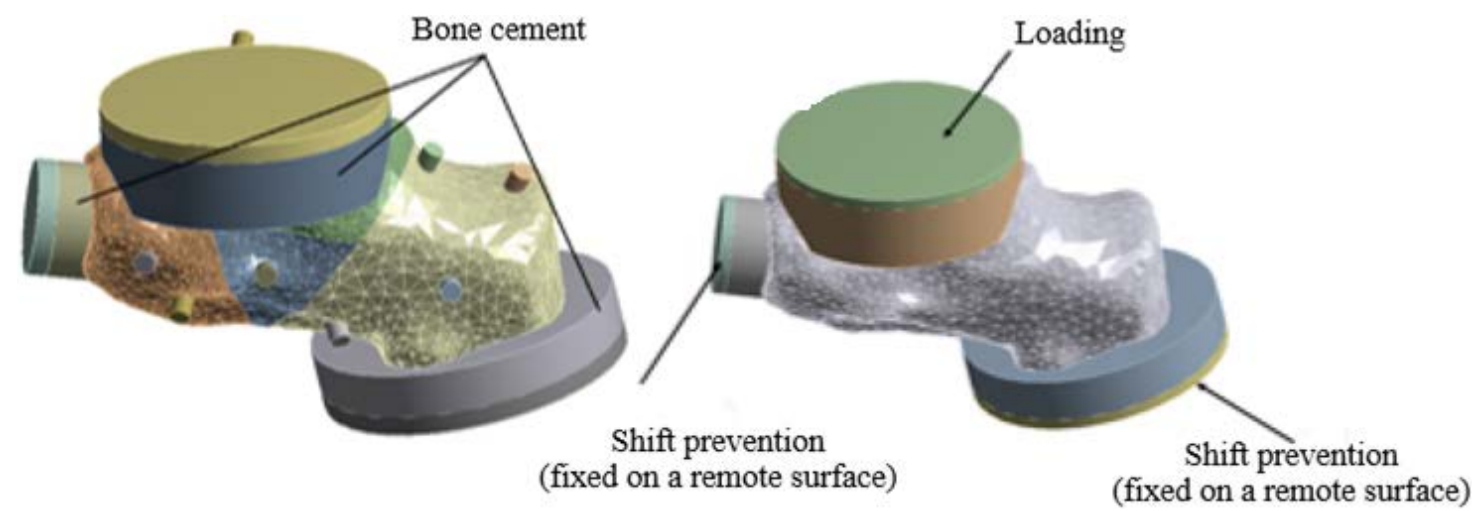

Fig. 6: Boundary conditions (mechanical contacts and loading).

The first computational model of a „healthy“ calcaneus was created, and thus the heel bone was not broken into individual fragments, but remains solid. The patient weigh $m=120 \mathrm{~kg}$ and gravity acceleration $g=9.81 \mathrm{~ms}^{-1}$ were considered for calculation. The calculations were carried out for a dynamic value, which can be transferred to the C-NAIL by the total dynamic force of patient $F$ including dynamic co-efficient of $K_{d}=1.4$ which simply transfers the static task into a dynamic task. According to

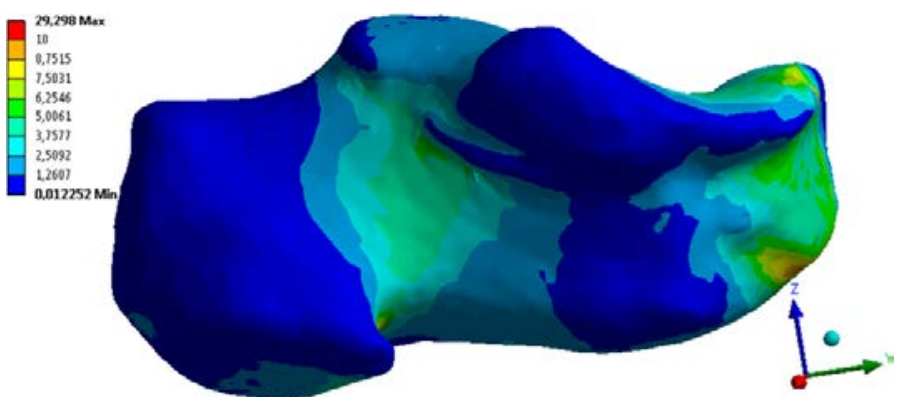

Fig. 7: Equivalent von Mises stress distribution /MPa/ on a calcaneus without fracture. the small possibility of higher overloading during the biginning of treatment (i.e. rehabilitation), the $K_{d}=1.4$ was chosen. Hence

$$
F=K_{d} \times m \times g=1647.6 \mathrm{~N}
$$

The calculation was carried out using Ansys Workbench 16.2 software.

The equivalent von Mises stress distribution is displayed in Fig. 7, the areas with higher reduced tension indicate places most prone to fracture of calcaneus. The resultant courses of reduced tension were presented to experienced physicians, who agreed on creating fracture lines, which corresponded to the fractures of the real bone.

The C-NAIL is made up of Ti6Al4V alloy by machining or 3D metal printing. This alloy is one of the most frequently used titamium alloys and its use it suitable in airplanes, biomedical materials, etc. It has excellent biocompatibility, mainly if it is required for directly connecting tissue to bone (replacement joints).

A strength analysis of the C-NAIL (with the same loading, see eq. 1) was also done on bones which were cut into 7 fragments (compound fracture). Mechanical contacts were thus only implemented between passing screws and the individual calcaneus fragments. This analysis is a simulation of an extreme situation that should not normally occur in reality, and this condition can be imagined as walking on an unsteady heel bone.

The maximum von Mises equivalent stress in C-NAIL (387.1 MPa) is located on the screw passing through the fragments of the heel bone, see Fig. 8. The maximum von Mises equivalent stress is lesser than yield strength $1000 \mathrm{MPa}$ (i.e. C-NAIL is quite safe) The medial upper part of the heel bone tends to move downward, causing increased tension. Thus, the bulk of the load is transferred by the C-NAIL heel bone because of the absence of contact between the individual fragments of the heel bones. 


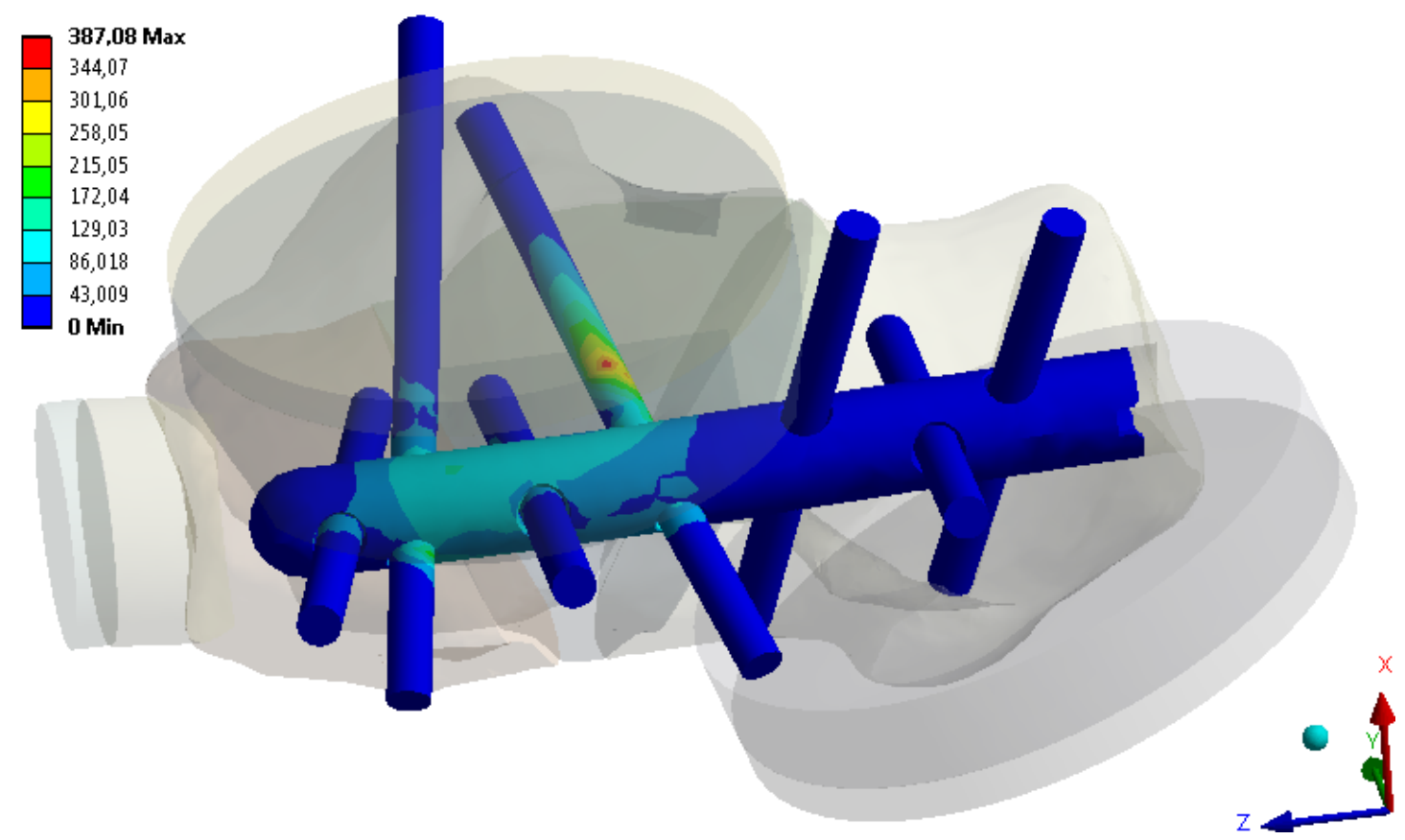

Fig. 8: Equivalent von Mises stress distribution /MPa/ on a calcaneus with fracture and with the C-NAIL and screws.

\section{Conclusion}

From the results of numerical analyses we can conclude that the C-NAIL is firm and stiff enough. It has become a standard type of surgical treatment with faster convalescence. The higher reliability of the CNAIL as opposed to the heel plate has also been confirmed by fatigue experiments carried out at a university in Rostock (Reinhardt et al., 2016).

\section{Acknowledgements}

The paper was supported by Czech project SP2019/100 and projects CZ.02.1.01/0.0/17_049/0008407 and CZ.02.1.01/0.0/0.0/17_049/0008441 within the Operational Programme Research, Development and Education financed by the European Union and from the state budget of the Czech Republic.

\section{References}

Martini, H. F., Tallitsch, B. R. (2015) Human anatomy, $8^{\text {th }}$ edition, Pearson, 896 pp, ISBN13: 9780321883322 Stehlík, J., Štulík, J. (2005) Calcaneal fracture. $1^{\text {st }}$ edition. Praha: Galén, 107 pp, ISBN 9788072626595.

Richter, M. (2006) Polyaxially-locked plate screws increase stability of fracture fixation in an experimental model of calcaneal fracture. Journal of Bone and Joint Surgery - British Volume, 88-B(9), 1257-1263, DOI: 10.1302/0301620X.88B9.17822. ISSN 0301620x.

Keyak, H., Falkinstein, Y. (2003), Comparison of in situ and in vitro CT scan-based finite element model predictions of proximal femoral fracture load. Medical Engineering \& Physics [online], 25(9), 781-787, DOI: 10.1016/S1350-4533(03)00081-X. ISSN 13504533.

Yosibash Z., (2012) p-FEMs in biomechanics: Bones and Arteries, Computer Methods in Applied Mechanics and Engineering, 249-252, s. 169-184.

Reinhardt, S., Martin, H., Ulmar, B., et al (2016) Interlocking Nailing Versus Interlocking Plating in Intra-articular Calcaneal Fractures: A Biomechanical Study. Foot \& Ankle International [online]., 37(8), 891-897 DOI: 10.1177/1071100716643586. ISSN 10711007.

Sejda, F., Frydrýšek, K., Pompach, M., Litner, R. (2015) Biomechanics - Elastic Foundation Applied in Modelling of Calcaneal Nails, Scientific Proceedings 2015, Faculty of Mechanical Engineering. STU in Bratislava. Vol. 23, Issue 1, Pages 12-17, ISSN (Online) 1338-5011, DOI: 10.1515/stu-2015-0003.

Frydrýšek, K, Šír, M., Pleva, L. (2018) Strength Analyses of Screws for Femoral Neck Fractures, Journal of medical and biological engineering, Vol. 38, Issue:5, pp. 816-834, DOI:10.1007/s40846-018-0378-x.

Frydrýšek, K., Machalla, V., Fojtík, F., Pleva, L. (2018) Torsion test for femoral, humeral and tibial nails. Engineering mechanics 2018, 24, ISSN 1805-8256, pp 225-228. 